This is a preprint of an article published by Taylor \& Francis in Housing \& Society on 02 April 2020, available online: https://doi.org/10.1080/08882746.2020.1740563.

\title{
Ageing well with chronic pain in rural areas: an ecologically informed study
}

\author{
Tom Kingstone $^{a b^{*}}$, Carolyn Chew-Graham ${ }^{a b c}$, Bernadette Bartlam $^{\mathrm{d}}$ \\ ${ }^{a}$ Versus Arthritis Primary Care Centre, School of Primary, Community and Social Care, Keele \\ University, Staffordshire, ST5 5BG, UK. \\ ${ }^{b}$ Midlands Partnership NHS Foundation Trust, St George's Hospital, Staffordshire, ST16 3SR, UK. \\ ${ }^{c}$ NIHR Applied Research Collaboration (ARC) West Midlands, Keele University, Staffordshire, ST5 \\ $5 B G U K$ \\ ${ }^{d}$ Lee Kong Chian School of Medicine, Nanyang Technological University, 50 Nanyang Ave, \\ Singapore, 639798.
}

\begin{abstract}
Over half of people in the UK aged 75 years and over experience chronic pain - defined as pain lasting three or more months. Chronic pain can impact activities of daily living, quality of life and independence. Rural perspectives on ageing with chronic pain are rare despite demographic trends indicating rural populations are ageing faster than urban populations and with an increasing prevalence of long-term painful conditions. Through interviews and observations, we explored experiences of rural older people with chronic pain. Our inquiry was framed by the ecological model of wellness developed by Winterton et al. (2016), which argues that socio-spatial and resource environments are crucial in nurturing and developing individual opportunities and competencies, promoting positive perceptions of the environment, and in contributing to overall health. Through an adapted constructivist grounded theory, our analysis revealed three key concepts, each an on-going process of (re)negotiating relationships between health and the rural environment: 'Life coming inwards', 'Managing chronic pain', and 'Maintaining meaning'. Findings highlight the relational nature of rural environments and key factors inherent in supporting people to adapt to age well with chronic pain. Implications for our understanding of processes of ageing well, future research, and policy and service provision are considered.
\end{abstract}

Key words: rurality, ageing well, chronic pain, exploratory methods

\section{Introduction}

In the United Kingdom (UK), the rural population is reported to be ageing faster than its urban counterpart; this is due to patterns of inward migration of middle and older aged adults from, and 
outward migration of younger people to, urban areas (Department for Environment Food \& Rural Affairs [Defra], 2019). Between 2001-2007 the population of those of pension age increased by 15\% $(330,000)$ in rural areas compared to $4 \%(303,000)$ in urban areas; between $2009-2029$, the population aged 65 and over is projected to increase by $62 \%$ in rural areas compared to $46 \%$ in urban areas with the increase higher amongst those aged 85 and over (114\% and 86\% respectively) (Oxford Consultants for Social Inclusion [OCSI], 2009). Age-related long-term conditions are projected to increase more rapidly in rural areas, with depression, stroke, falls and dementia expected to increase by between 50$60 \%$ compared to $34-42 \%$ in urban areas over the next 15 years (OCSI, 2009).

Health beliefs and perceptions of one's own health have been shown to be an important indicator of quality of life amongst older people (Smith et al., 2004); older people commonly have low expectations around quality of life as they age (Scharf \& Bartlam, 2006). Limited material resources, poor quality social relationships, lack of access to services, and changes within rural communities can interact to reduce well-being, with life course factors and life events contributing to exclusion in later life (Brundisini et al., 2013; Hennessy et al., 2013; Rural England, 2017; Scharf \& Bartlam, 2006; Stuckler et al., 2017; Wenger \& Burholt, 2004). Evidence suggests that rural residents face complex decisions regarding access to healthcare and that a plethora of socio-cultural and economic factors influence illness behaviours among older rural residents (Farmer et al., 2006). However, there remains an ongoing weakness in the evidence base for rural ageing (Scharf \& Bartlam, 2006; Shucksmith, 2003), and such paucity contributes to the perpetuation of stereotypes concerning rural ageing (Wenger, 2001). For instance, rural communities are widely perceived to be close-knit and supportive; rural older people are considered to have fewer service needs because they are healthier and more satisfied with life than their urban counterparts (Wenger, 2001). There is a popular perception that rural older people are a relatively advantaged social group (Bell \& Jayne, 2010). However, evidence from a range of countries including the UK suggests that older people in rural areas experience worse long-term health conditions and socio-economic outcomes than the general older population (Rural England, 2017). This may be explained by disparities between apparently objective assessments of disadvantage and rural older peoples own subjective accounts. For example, older people living in low-income households may seek 
to qualify their experiences by emphasising more positive aspects of rural life (Philip \& Shucksmith, 2003). This in turn reflects a prevalent attitude amongst rural older people that emphasises notions of self-sufficiency, independence and pride (Scharf \& Bartlam, 2006; Wenger, 2001).

In this paper, we explore the lived experiences of rural older people with chronic pain in order to better understand the adaptive processes they draw on to age well. No previous study has explored experiences of chronic pain among rural older people in these contexts. We utilise an ecological model of wellness (Winterton et al., 2016) to determine individual, social and environmental factors that support ageing well and to frame implications for older people, health and care services and future research. Approval was obtained from Keele University’s Ethical Review Panel

\section{Chronic pain and ageing}

Chronic pain is defined as persistent or recurrent pain of at least three months' duration (Treede et al., 2015) and is usually attributed to an underlying musculoskeletal condition (e.g. osteoarthritis). It is reported by 35-51 per cent of the UK population with prevalence increasing with age (Fayaz et al., 2015). Chronic pain can cause disability and have deleterious effects on quality of life (Ndao-Brumblay \& Green, 2010). Previous research exploring older adults' experiences of chronic pain has focused on the role of adaptation in the face of disability. Sofaer-Bennett et al. (2007) identified how participants strived to maintain control and independence through adaptation of activities; including selective reduction of activities. Similarly, Mackichan et al. (2013) described an overarching theme of 'living within your limits' in their qualitative study of older people with chronic pain. The theme captured how participants negotiated reductions or alterations in their activity levels - both social and physical activities - to maintain autonomy; such adaptations had negative implications for physical functioning, disability and social isolation.

\section{Ecological perspectives on ageing well}

Wellness is defined as 'the optimal state of health of individuals and groups' (World Health Organisation [WHO], 2006: p5) and relates to the fulfilment of one's physical, psychological, social, 
spiritual and economic potential. Attributes of wellness are described through concepts such as quality of life and wellbeing; although these are not analogous to wellness (Rachele et al., 2013). Various models of ageing well have been developed to understand wellness through the prism of ageing; adopting a strengths-based approach to identify factors that support older adults to maintain well-being in later life.

The importance of environmental and social resources in supporting people to age well are widely acknowledged (Chapman, 2009; Lawton 1983; Rowles 1978, 1983; Rowles \& Bernard, 2013). Several models of ageing well exist to help make sense of the complex relationships and interchanges between people and places over time (Bowling, 2005; Lawton \& Nahemow, 1973; Wahl et al., 2012). However, such models often neglect the role of long-term health conditions, a common experience in later life, and how changes in health status impact upon and are structured by person-environment dynamics.

Wahl et al. (2012), building on the seminal work of Lawton (1983) and the person-environment interchange, argued that implicit to ageing well is the maintenance of '... the highest autonomy, wellbeing, and preservation of one's self and identity as possible, even in the face of severe competence loss.' (Wahl et al. 2012: 310). They distinguish two key processes in their model of ageing well. The first is experience-driven belonging (connection between people and place); the second is behaviourdriven agency (individuals making changes in life through intended actions). Sofaer-Bennett et al. (2007) and Mackichan et al. (2013) described adaptation in the face of competence loss in the context of chronic pain; however, they did not consider challenges to identity and/or personal agency.

Within a paradigm of wellness, it is important to identify the positive aspects of the personenvironment interchange that enable older people to overcome disparities in rural resources (Means et al., 2014). Winterton et al. (2016) switched the focus from individualistic models of ageing well to construct a community ecological model of wellness for rural older adults; they argue that socio-spatial and resource environments are crucial in nurturing and developing individual opportunities and competencies, promoting positive perceptions of the environment, and in contributing to overall health and wellbeing. The model positions objective rural community characteristics - defined as either socio- 
spatial or resource-based - as influencing wellness at three distinct levels: (1) opportunities and capabilities, (2) perceptions of the environment, and (3) objective and subjective measures of health and well-being. The authors describe resource-based characteristics (including the built, natural and service environments) as having direct impacts on the three levels of wellness for older adults due to greater proximity. Socio-spatial characteristics (including socio-demographic and spatial factors) are described as more distal; having both indirect influences (socio-spatial characteristics influence resource environments) and direct influences at the three levels.

In addition to using the model proposed by Winterton et al. (2016) we also incorporated a relational perspective on rurality (Cummins et al., 2007; Macintyre et al., 2002) and consider rural environments to be places in which health and illness occur and also with which such experiences are negotiated in a dynamic, on-going process; these environments are simultaneously material, symbolic and social spaces (Heley \& Jones, 2012).

\section{Materials and methods}

In keeping with the principles of social gerontology (Bernard \& Scharf, 2007), i.e. doing research with rather than to older people, the study was guided throughout by a Research Advisory Group, comprising rural older people with self-reported chronic pain, a retired rural General Practitioner (GP) and representatives from third sector organisations active in rural communities. The group provided ongoing advice throughout the research on aspects including: research design, selection of methods and participant-facing study documents to check suitability, and contributed to a stakeholder workshop at the end of the study as part of dissemination to increase impact.

\section{Recruitment}

Whilst Sherry and Shortall (2019) warn against assimilating "all rural areas into one undifferentiated aggregate, with urban as the other", for the purposes of this research a pragmatic definition of rural was used with rural areas defined as open countryside or settlements with fewer than 10,000 people i.e. nonurban (Defra, 2019). The research was conducted in the Staffordshire Moorlands (England). This area 
is 57,600 hectares in size, predominantly rural ( 89 per cent) and ranked in the top $40 \%$ of most deprived areas in England. The population comprises 97,000 people, has the oldest demographic profile of the eight districts in Staffordshire, with a life expectancy of 81.6 years, and only 2.5 per cent of this population are non-white (Staffordshire County Council, 2018).

The sampling strategy was purposive with the following inclusion criteria: aged 65 years and over at the start of participation, self-reported chronic pain (three or more months), living in one's own home (i.e. not in institutional settings) in a rural setting. Snowball sampling techniques (Silverman, 2013) were used to support recruitment from seldom heard populations (e.g. older men) (Faugier \& Sargeant, 1997). At the outset, we anticipated that approximately 10 participants would provide sufficient data for analysis, given the in-depth, multi-method nature of the data collection; this was reviewed as part of an iterative approach to analysis and in the light of data saturation (Saunders et al. 2017).

Potential participants were identified through local third sector organisations and community groups (e.g. Age UK, Mothers Union, Women's Institute). The lead author attended community groups to share information about the research with potential participants and gatekeepers, invite people to share details of the research with others, and welcome expressions of interest to take part. In total, 60 study information packs (comprising: invitation letter, participant information sheet, consent to further contact sheet, pre-paid return envelope) were distributed by the lead author, gatekeeper or via snowballing to individuals who expressed an initial interest in the study. Only individuals that completed and returned a 'consent to further contact' sheet were contacted to arrange an interview. Participants were recruited from five different villages in the Staffordshire Moorlands, which varied in population and area size, access to services (e.g. GP surgery, shops, bus services) and amenities (e.g. main roads, pavements, street lighting). 


\section{Data collection}

Data collection occurred over nine months in two stages. Ethnographic observations were systematically documented throughout data collection in written fieldnotes. The lead author conducted all data collection.

A semi-structured interview was conducted in stage one. A topic guide was developed through discussion with the research team, the research advisory group, and informed by the literature, to cover topics of health and pain experiences, coping strategies, social activities, and home and environment (see Appendix 1). The CASP-19 (Hyde et al., 2003), a needs-based quality of life measure validated for use with older adults in the UK, was incorporated into the interview as a descriptive indicator of wellness. The CASP includes 19 items, measured on a 4-point scale, across the four domains (described above). The domains can be scored individually, and overall scores range from 0-57 with a high score denoting better quality of life.

In stage two, participants were provided with a choice of follow-up method, options included:

(1) Photo-elicitation interview (Prosser, 2006) taking an auto-photography approach (Hinck, 2004) in which participants were invited to use existing photographs or create new photographs, using a camera provided, that meant something to them in the context of chronic pain. The photographs were then used in a face-to-face interview in which participants were asked to describe each photograph, its meaning in the context of chronic pain and/or rurality, and why they selected/created it;

(2) 'Go-along' interview (Carpiano, 2009; Kusenbach, 2003; Rowles, 1978), which involved the researcher accompanying the participant on a routine activity with the route determined by the participant (e.g. a walk around local neighbourhood, shopping etc.). Activities were recorded through photographs, digital recording (audio), and fieldnotes to facilitate exploration of individual-environment relationships and observe chronic pain in everyday activities; 
(3) Semi-structured interview with a topic guide developed from the stage one interview.

The follow-up methods were selected to capture key interactions, support creativity and autonomy, and promote inclusivity. The options for follow-up were discussed and agreed with participants at the end of stage one interviews. Participants retained the right to opt-out of further data collection.

\section{Analysis}

Analysis was informed by constructivist grounded theory processes: coding, refined coding, categorising, annotating, memo writing and constant comparison (Charmaz, 2014). Interview transcripts, fieldnotes and photographs were all coded in the following stages: (1) individual datasets, (2) cross-case comparisons, (3) categorising of common codes, and (4) development of conceptual categories. Analysis stopped when no new properties of the conceptual categories emerged; a saturation of data (Saunders et al., 2017) as opposed to theoretical saturation (Charmaz, 2014). Data analysis was led by the lead author, with a random selection of data independently coded by the second and third authors to check reliability of the analysis. NVivo 10 (QSR International) was used to support management of data and analysis. Quantitative data from the CASP were calculated (domain and total scores) and included in participant characteristics information.

A selection of verbal and visual data is presented in the findings; these are labelled by participant identifiers (pseudonyms) and data collection activity (i.e. type of interview or fieldnotes). Pseudonyms have been used to maintain anonymity. These were used to convey respect to the participants and were selected to maintain cultural relevancy (British names considered to be ageappropriate) and a sense of authenticity (maintains link to individual experiences). Consecutive letters of the alphabet were used as the first letter for each pseudonym; this followed the order in which participants were recruited onto the study. Photographs were altered (e.g. blurred, cropped) to remove identifiable information and maintain anonymity. 


\section{Results}

\section{Participant characteristics}

Eight people (four women, four men; mean age 78 years) participated in the study. All participants were White British, reflecting $97.5 \%$ of the local population, and all but one was retired from formal employment. Half were living alone and all but one participant had lived in their current location for 10 years or more. The mean average quality of life scores was 37/57, with the lowest being 25/57 and the highest 49/57 (see Table 1). The spouses of three male participants also took part in data collection, at the request of the participant, and contributed data during interviews. Consent to use their data in analysis and publication was obtained but demographic information was not collected.

\section{Table 1 here: participant characteristics}

All participants reported chronic musculoskeletal pain in more than one site, with five reporting back pain. Duration of pain ranged from 3-40 years, with participants describing it as impacting on everyday activities and fluctuating over time. See Table 2.

Table 2 here: chronic pain descriptions

Eight stage-one interviews and six follow-up data collection activities were completed; two participants declined follow-up, see Table 2 (see Discussion section for further reflections). Overall, data comprised 29 hours of audio-recorded data from interviews, a fieldnote journal, and 101 photographs taken by participants (for the purposes of photo-elicitation interviews) or the researcher during go-along interviews or to supplement fieldnotes.

Table 3 here: data generation activities 


\section{Conceptual categories}

Three conceptual categories were identified in the analysis: (1) Life coming inwards contextualises the restrictive nature of chronic pain; (2) Managing chronic pain refers to different dimensions of pain management and the role of rurality, and (3) Maintaining meaning captures the compromises and adaptations participants made to maintain attachment (or not) with rural places in the context of pain.

\section{Life coming inwards}

All participants reported interference from chronic pain in everyday life (Table 3). Such interference contributed to a sense of life becoming restricted with various dimensions of restriction described. Frances (67-year-old female; pain in lower back and hip) reflected on the impact on physical activities:

"You're maybe doing stitching or whatever and you can't get into a comfortable position or if you go out for a walk, you're only walking a little way and then you start getting the pain, and you just feel as if your life is starting to come inwards." (Frances, interview 2)

George (74-year-old male; pain in feet and ankles) - a farmer for over 50 years - spoke of his physical limitations using an example of a damaged wall near to his home to illustrate his frustration and limitations (see Figure 1):

"[Others] seem to drive past and never see them. There's a wall you know! Falling down. And they just go straight past it and never see it, or don't want to see it. I don't know which it is. It's things like that I wish I could deal with.” (George, interview 1)

Figure 1. George's drystone wall 
Similarly, David (70-year-old male; pain in lower back, elbows and hands) described progressive physical limitations as a consequence of pain and the impact these have on his participation in biographically meaningful activities. David's interviews revealed an identity constructed around home improvements and DIY; however, recent to the interview he had started to give away his tools:

"I've started giving him [son-in-law] some of my tools. [...] I've got a saw but it's too heavy, I can't hold it now, so I gave him that the other week. [...] The Sunday when he was here, he'd said that his strimmer wasn't working very well. I said, there's one in the garage there, take that with you" (David, interview 2)

David's actions seem symbolic, even ceremonial, representing an act of acceptance of his restrictions.

The impact of restrictions imposed by chronic pain could affect others, for example, Gail (George's wife) seemed to share in George's restrictions; this reduced the size of their shared world:

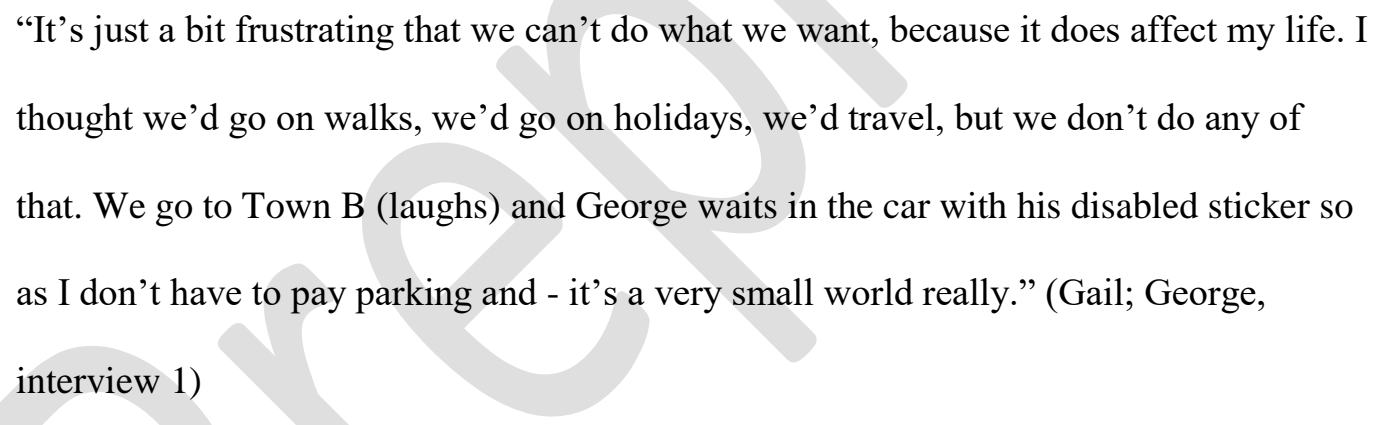

\section{Adapting to manage chronic pain in a rural setting}

Participants described chronic pain management in relation to: (1) managing pain itself, and (2) managing the associated disability, each nuanced by rural contexts and biographical factors.

\section{Managing pain itself}

All participants reported using pharmacological medication (i.e. painkillers) to manage their pain whether obtained on prescription or purchased over-the-counter (see Table 3). Anne (82 year-old female; pain in lower back, shoulder, hip and hands) seemed to rely on painkillers as her sole pain 
management strategy, she describes their effectiveness as limited, sufficient to enable her to complete a few domestic tasks:

"I do a job or two perhaps, and then it [pain] comes on, and then I have to sit down. I just take it every day as it comes like that." (Anne, interview 1)

Henry (78-year-old male; pain in abdomen and lower back) described painkillers as practically useless:

"They might as well have given me jelly babies. I'd have enjoyed them better (laughs)."

(Henry, interview 1)

Despite ongoing pain and the apparent ineffectiveness of painkillers, participants seemed reluctant to seek additional help from healthcare services for their pain. For some, engagement with General Practitioners (GPs) was limited only to the renewal of painkiller prescriptions:

"I went [to my GP] last week, but only to pick up my tablets" (Barbara [78-year-old female; pain in shoulders, hands and feet], interview 1)

Anne implied chronic pain as not a worthwhile use of a GP's time:

"I don't believe in running to the doctors unless you're ill" (Anne, interview 1).

Furthermore, Anne's perception of her condition reflects a sense of stoicism; by not attending the doctors she is able to preserve this sense and support her coping strategy. By not engaging with healthcare services, participants inadvertently reduced their opportunities to discover alternative pain management strategies. For instance, Frances described utilising a mix of different strategies stemming from her engagement with various services:

"I've been able to exercise and do what the physio has asked me. I've started to do more yoga, and it has eased. I'm not taking so many tablets. And I can do more things so I don't feel as though I am tied to the house. I can actually go out and walk without being doubled up.” (Frances, interview 1) 
Accessing different pain management resources (physiotherapists, alternative therapies) typically required access to information and transport, to reach services not provided in the immediate environment. Participants who had experienced pain for longer displayed a greater awareness of alternative pain management strategies (e.g. Frances [pain for 20 years] and David [pain for 40 years]); more time to identify what works for them.

Edward (81 year-old male, pain in lower back and hip) highlighted some of the competing challenges that could limit healthcare utilisation:

"I actually drive myself the short distance [100 metres to GP surgery], I feel a bit what you might called ashamed about it. I should be able to walk it but I can't so there you go..." (Edward, interview 1).

Disability, distance to services, access to transport and issues of pride are apparent here. For participants like Edward, who retained access to a car and the capacity to drive, healthcare services remained accessible despite distance, personal disability and potential shame. In contrast, for those without access to a car, attending their GP surgery was more challenging. For example, in the case of Anne, her nearest GP surgery is 4 kilometres away. She cannot walk to the surgery; mobility problems and inadequate footpaths prevent this, and the local bus service she described as:

\footnotetext{
"It's not very convenient, going on bus... [and] now they've knocked all these subsidises off. We've got to pay full fare." (Anne, interview 1)
}

Anne would therefore need to pay for private transport or negotiate a favour from a family member; these solutions have implications both financially and socially - being in another's debt which may inadvertently threaten her sense of stoicism.

\section{Managing disability}

Participants described managing their disability through various adaptations, for example, assistive aids were integrated into everyday life to support mobility. Anne uses a walking-frame when out of the 
house; this was observed during her 'go-along' interview, which included visiting a local town centre. Figure 2 and 3 present data from fieldnotes (photographs and observations) collected from the go-along.

Figure 2 and 3 here (images and observations from go-along with Anne)

Figure 2 and 3 highlight the challenges of managing assistive aids in urban environments purposefully designed to be pedestrian-friendly. However, the lack of adequate footpaths and street lighting outside Anne's house means the walk to the nearest bus stop ( 100 metres), even with her walking aids, presents a challenge.

The use of assistive aids also prompted unwanted attention relating to issues of self-image and pride. George uses a walking-frame and has orthopaedic shoes but is conscious of the visibility of these aids and therefore his health problems and how this impacts on his identity. The orthopaedic shoes for instance are cumbersome and ugly:

“...they're not dancing shoes”. (George, interview 1).

They are instead:

“...silly boots" (George, interview 1).

Like Anne, George is aware of how he is perceived by others and reports a preference to keep the use of these devices to within the boundaries of his home. This is important in terms of maintaining his sense of identity but inadvertently reduces his social participation and increases his isolation.

\section{Maintaining meaning in rural life}

This conceptual category reveals how, despite pain and its restrictive nature, participants maintained meaning in life. Individually held notions of rurality, informed by biographical factors, were critical to shaping meaning in the lives of participants. 


\section{Maintaining a sense of connection to 'the rural'}

Maintaining a sense of connection to symbolic aspects of rural environments provided a source of meaning for participants. For Henry, rural environments represent fresh air, good health and long life:

"I mean, you'd think the people up here would live forever. There's no dust from anything, you know, [not the] same as what's in towns." (Henry, interview 1)

Participants described connecting with pleasant, aesthetic features of rural landscapes to gain therapeutic benefits. During the go-along, Henry included one of his "favourite places" in the Staffordshire Moorlands; a place he would often visit to enjoy the view, as depicted in Figure 4:

Figure 4 here (Henry favourite beauty spot)

Other participants described utilising aspects of the natural environment to support their sense of wellbeing, for example, how seeing flowers in bloom elevated mood.

Frances described a physical connection with nature through her newly developed passion for gardening, an activity that she started after moving to the village following retirement:

"I found out I like getting my hands in the [...] compost or the soil. I like that. I enjoy that, which I didn't think I ever would, so I've learned a [...] little about myself." (Frances, interview 2: photo-elicitation - referring to Figure 5)

Figure 5 here (Frances conservatory) 
For Frances, gardening - sharing and taking pleasure from a physical connection with nature symbolises her sense of connection to rurality and supports an identity she is seeking to establish in retirement. In contrast, George's rural identity is linked to farming; his family have been involved in farming for three generations. However, as described in relation to the drystone wall (Figure 1), the surrounding environment acts as a reminder of what he can no longer interact with, diminishing his sense of connection to farming and to rurality.

Being accepted by others in rural communities was identified as important for some participants. Catherine (90-year-old woman; pain in hip and right buttock), who has lived in her village location for over 50 years, remains conscious of feeling or being labelled by some as a relative outsider (i.e. not having been born and/or raised in the village):

\footnotetext{
"The couple that take me to the lunch club [...], I said to her about six months ago, do you think I qualify for membership of the village yet? And she said, well, you're getting there." (Catherine, interview 1)
}

Village membership seems important for Catherine to support her sense of belonging, and this is maintained through relationships with others. However, Catherine described the impact of her disability:

\footnotetext{
"I mean it prevents me - we've said gardening, it prevents me driving, it prevents me trotting round the village visiting people." (Catherine, interview 1)
}

Disability may diminish Catherine's interpersonal connections and sense of place, and increase her risk of becoming isolated.

\section{Maintaining meaningful activities}

Participants described transforming the ways in which they participated in meaningful activities to overcome limitations of chronic pain; this relied on individual resourcefulness. David described making 
several adaptations; changes were often discreet but no less significant, for example, he replaced his petrol-engine lawnmower for an electric lawnmower:

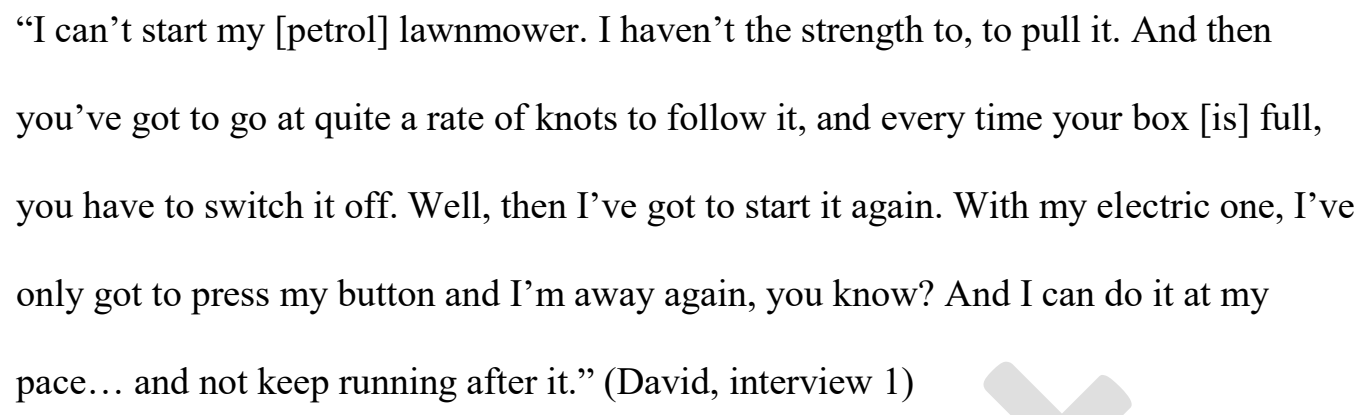

This adaptation provides a means to an end. The 'end' in this instance has greater symbolic value than the act of mowing the lawn; David reinforces identities of home maintenance and property development, which represent significant biographical threads for him that are intimately tied to the local area.

Catherine reflected on her fondness for walking and exploring the countryside:

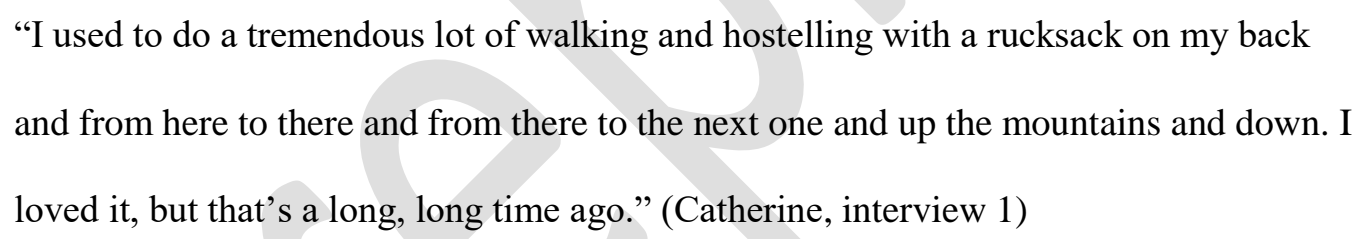

To maintain a sense of connection to nature, Catherine purchased a set of books from the National Trust, which include photographs of the places she previously visited. The pictures prompt memories of these meaningful places and transform her participation from physical-spatial to imaginary, through reminiscence Catherine maintains her connection with nature:

\footnotetext{
"Just going through them [the books] and finding the walks that I've actually done and those beautiful views. There are eight of them, and I whisked through them all when I got them, and now, one at a time, I'm really going through them, and getting enormous pleasure. I can think, yes, that's the path I walked along and, that's the peak I climbed or, I've been there. [...] And the people I was with when I was doing it." (Catherine, interview 1)
} 


\section{Developing new networks and sources of identity}

Third sector organisations operating in and around rural areas provided opportunities to access new sources of meaning and relationships. Anne, Barbara, and Catherine attend luncheon clubs regularly; these clubs provide opportunities for participants to socialise with a cohort of similarly aged people, predominantly women from the surrounding geographical area. Anne described how these clubs support her needs:

"It's just a little get together to get out because we all like it, because we think it's just a get out for an hour or two from four walls. I'm picked up here [from home] by a minibus and brought back. I've no walking to do or anything." (Anne, interview 1)

The provision of transport was crucial to participants who were socially isolated, did not have access to a car, and/or for whom public transport services were limited. For Anne, attending the luncheon club supports social participation and connection with others in the village whilst distracting her from ruminating about pain. These groups do not provide the same benefits for all participants, as Barbara described:

"That's the only [luncheon club] I go to, me daughters make me go" (Barbara, interview 1).

Male participants did not access luncheon clubs or other third sector groups. David and Edward described attending their local church on Sundays; however, family seemed to provide a greater source of meaning than religion. Henry described maintaining an after-work routine of frequenting the local pub, which reinforced his employment identity and independence.

\section{Discussion}

Older adults' experiences of chronic pain and self-management were embedded within the rural contexts in which they lived. The three key conceptual categories to emerge from the analysis: 'Life coming inwards', 'Managing chronic pain', and 'Maintaining meaning in life' capture distinct yet 
interconnected and dynamic aspects of ageing well with chronic pain in a rural environment. We present the relationship between the conceptual categories in a visual diagram (see Figure 6).

Chronic pain was described as disabling and revealed multiple levels of interference in everyday life. The restrictive nature of pain contributed to a sense among participants of their worlds coming inwards; impacting participation in social life, reducing the length of walks, diminishing connections to meaningful activities and symbols of those activities (e.g. home improvements and power tools). Mixed pain management strategies (i.e. painkillers, physiotherapy exercises, alternative therapies e.g. yoga, reflexology) seemed most effective for pain management; however, this was often facilitated by duration of chronic pain and adjustment to it. Adapting to disability (i.e. accepting and integrating assistive aids) was also important; assistive aids supported participant's level of mobility and the completion of everyday domestic tasks but threatened self-image, increased the visibility of disability and had limited applicability in rural environments due to lack of age-friendly design. Attitudes towards help-seeking from GPs, disability, and access to transport presented challenges to healthcare utilisation revealed inequalities at individual and community levels.

Meaning in life was tightly bound to rurality; sources of connection were driven by individually held notions of, and attachment to, 'the rural'. Participants strived to maintain activities that represented biographically significant roles and identities; this was achieved, where possible, through processes of adaptation and transformation. The loss of activities that were meaningful and/or supported an individual's sense of rural belonging limited their capacity to age well.

\section{Strengths and limitations}

This study highlights the importance of taking a relational and critical approach to the role of environments in the context of ageing with chronic pain. The mix of methods applied in this study produced a rich dataset for analysis. The sample was diverse in terms of: age, sex, education, time spent with chronic pain, site of pain, and attributed cause of pain. However, due the relatively small sample, important views may be missing that could have implications for findings as the eight participants were homogeneous in terms of: ethnicity (white British), living in a single district and similar settlement 
(villages), and home ownership. No single men or married women were recruited (data on sexuality was not disclosed). Findings are therefore limited to those attributes and characteristics described in the sample.

The research design was informed by patient and public involvement (PPI) which supported the use of multiple follow-up methods and the presentation of options. The PPI group valued the flexibility and level of autonomy this approach afforded participants. Whilst follow-up methods added richness to the data and supported engagement from most participants, the small sample presents a lack of consistency in the application of methods across the study. Of the two male participants that declined follow-up interviews: one participant stated they had nothing further to add to the topic; the second, having initially agreed to participate in a photo-elicitation interview, later declined by telephone stating that the method did not suit them although other options were discussed. Issues of gender and/or attitudes related to stoicism and privacy may have underpinned these decisions; however, these factors could not be explored. Chronic pain-related restrictions, whilst an important aspect to explore in this study, also presented a challenge to data collection as participants could not take part in specific methods (e.g. photography due to hand pain).

In cases where partners accompanied participants during interviews, their understanding of the study was checked and informed consent to use anything they might share as data was obtained. However, their contributions were limited to narrative data; socio-demographic data and CASP scores were not recorded. All participants except two reported co-morbid health problems in addition to pain and its underlying cause (e.g. osteoarthritis), but for the purposes of this paper discussion focused on aspects of chronic pain.

Despite the limitations described, this paper contributes useful insights on an under considered topic to guide future investigations. 


\section{Comparison with existing literature}

This research highlights the interconnectedness between chronic pain management and processes of ageing well; adding further emphasis to arguments that pain management provides only a means to an end (Richardson et al., 2015). A fundamental component of such self-management was stoicism (Blomqvist \& Edberg, 2002; Hunhammar et al., 2009; Morden et al., 2012; Schofield et al., 2008) integral to such a position was valuing privacy above potential benefits of disclosing pain to others (Gannon et al., 2013; Tollefson et al., 2011). This study reveals that by choosing not to discuss pain with others, for fear of being defined by pain, older people may inadvertently limit their opportunities to develop awareness of alternative pain management strategies. Furthermore, prioritising self-image may potentially mask vulnerabilities. Hidden vulnerabilities have been described in the context of care home settings where a high value is placed on privacy due to sense of ongoing scrutiny (Gudmannsdotir $\&$ Halldorsdottir, 2009). The same could be true in rural settings described elsewhere as places of 'pervasive watching' (Philo et al., 2017).

Findings from the current study suggest experiences of chronic pain are relevant across the domains of the ecological model of wellness proposed by Winterton et al. (2016): opportunities and capabilities, perceptions of environment, and perceptions of health and well-being. Each is described in turn with reference to resources and socio-spatial characteristics.

Opportunities and capabilities to access healthcare resources varied between participants due to environmental factors (e.g. built - infrastructure; natural - topography; services - lack of proactive support for self-management, inadequate public transport), psychosocial factors (e.g. coping strategies that relied on the preservation of pride, stoicism and privacy) and disability. Access to healthcare services was challenging due to the location of services in larger more densely populated villages (Walsh et al., 2017), and a lack of adequate transport services and/or infrastructure (e.g. access roads, pavements) to support older people to overcome physical disabilities (Menec et al., 2015). Third sector services and community groups represented important resources for older women, in particular, to maintain physical amenity-oriented and social forms of attachment to place; these networks helped 
overcome the loss of informal networks (i.e. dispersed family) and often provided door-to-door transport services to overcome disability and socio-spatial barriers (Philip et al., 2015). Insufficient access to voluntary sector services in rural and deprived areas is of growing concern, given the lifeline that they provide (Clifford, 2012).

Perceptions of environment had a direct influence on older adult's health and well-being and aspects of identity; the level of influence depended on disability associated with chronic pain, sociospatial characteristics (e.g. access to natural environments) and availability of resources (e.g. opportunities to participate in meaningful activities). The maintenance of self-identity was critically important to supporting ageing well in this study, as highlighted elsewhere (e.g. Wahl et al., 2012). Meaning was achieved by some older people in this study through rural belonging, which extended across the different dimensions of place attachment described by Burholt (2012): social (integration and support), psychological (personal and emotional well-being), physical (aesthetic qualities and appropriateness based on needs) and temporal (historical) dimensions. Reduced social participation, due to disability and/or inadvertently coping strategies that valued stoicism and privacy, inform our understanding of the role of health in relation to social exclusion in rural environments - to some extent exclusion is self-imposed (O'Sullivan et al., 2012; Sacker et al., 2017; Walsh et al., 2017).

Perceptions of health and well-being seemed directly related to rural environments through attachments linked to nature-bonding (Raymond et al., 2010). Older adults described interacting with pleasant features of rural environments (e.g. gardens, flowers in bloom, picturesque views) and individually held notions of rurality (e.g. fresh air, long life). Access to natural (green and blue) environments to support healthy ageing has been reported elsewhere among rural and urban populations (Bacsu et al., 2014; Finlay et al., 2015). Physical interactions with natural environments included activities such as gardening, which reinforced both old and new identities (e.g. gardener, nurturer, independence). Whilst gardening is by no means an exclusively rural activity, this activity represented a connection between people and their individually held notions of rurality and of home (Bhatti, 2006). However, for older people - particularly those with lifelong connections to rural places - aesthetic features of their immediate environments (e.g. the damaged dry-stone wall) reinforced emergent 
identities associated with disability; signifying loss of attachment. In terms of person-environment fit; failure to adapt forms of place attachment following loss of competence and declines in health seem important (Lien et al., 2015).

\section{Conclusions and implications}

To conclude this paper, we reflect on the implications of our findings and suggest opportunities for future research. The study has implications for understanding models of ageing well in the context of chronic pain, self-management and rural contexts. Issues of rurality have been shown to extend beyond objective problems of distance and access to services into identity and meaning making in later life. This study provides a foundation from which to further develop models of wellness for older adults (e.g. Wahl et al., 2012; Winterton et al., 2016) - such models need to better incorporate and recognise the impact of living with and managing long-term conditions. Future empirical research should critically apply, test and refine theories of wellness in the context of the diversity and complexity of rural environments.

The NHS Long Term Plan (NHS England, 2019) emphasises the importance of the selfmanagement of long-term conditions and the emergence of community-based healthcare. Given low healthcare utilisation by rural older adults, findings from our study highlight the need for healthcare services to adopt pro-active strategies to promote and support self-management (e.g. Public Health England). Findings also reveal important contributions from voluntary sector services as part of the healthcare landscape; future research should seek to further recognise the role of the voluntary sector in this context and establish components of best practice.

Natural environments also had an important role in supporting health, well-being and identity. Issues of inequality and inequity continue to pervade rural areas through differentiated provision of services and access to natural environments; these challenges were exacerbated by limitations imposed by chronic pain. Policies designed to support better access to green spaces for health and well-being (National Trust, 2017) and strategies to tackle loneliness (HM Government, 2018) should consider the 
needs of older rural residents. Future research should seek to develop novel place-sensitive interventions that support quality of life among older adults. 


\section{Statement of funding}

Original research was funded by Keele University through an ACORN studentship. First author's current role is funded by Midlands Partnership NHS Foundation Trust, St George's Hospital, Stafford, ST16 3SR. Last author's role is funded by National Institute for Health Research, Applied Research Collaboration (ARC) West Midlands, Keele University, UK.

\section{Declaration of contribution of authors}

Lead author - project conception, data generation, analysis, original draft

Second author -

Last author project conception, refining design and methods, reviewing data collection, analysis, manuscript drafting

\section{Disclosure statement}

No conflict of interest.

\section{Acknowledgement}

To Moorlands Homelink, Age UK Staffordshire, and local Women's Institute and Mothers Union groups for supporting participant recruitment. To the project advisory team for their ongoing support and guidance throughout the original study. To the Patient and Public Involvement and Engagement (PPIE) team at Keele University and Research User Group members for contributions to the development of the original study. 


\section{References}

Bacsu, J., Jeffery, B., Abonyi, S., Johnson, S., Novik, N., Martz, D., \& Oosman, S. (2014). Healthy aging in place: Perceptions of rural older adults. Educational Gerontology, 40(5), 327-337. https://doi.org/10.1080/03601277.2013.802191

Bell, D. \& Jayne, M., (2010). The creative countryside: Policy and practice in the UK rural cultural economy. Journal of Rural Studies, 26(3), 209-218. https://doi.org/10.1016/j.jrurstud.2010.01.001

Bernard, M. \& Scharf, T. (2007). Critical perspectives on ageing societies. In Bernard and T Scharf (Eds), Critical Perspectives on ageing societies. Policy Press.

Bhatti, M. (2006). 'When I'm in the garden I can create my own paradise': Homes and gardens in later life. The Sociological Review, 54(2), 318-341. https://doi.org/10.1111/j.1467-954X.2006.00616.x

Blomqvist, K. \& Edberg, A. K. (2002). Living with persistent pain: Experiences of older people receiving home care. Journal of Advanced Nursing, 40(3), 297-306. DOI: http://doi.org/10.1046/j.1365-2648.2002.02371.x

Bowling, A. (2005). Ageing well: Quality of life in old age. Open University Press.

Brundisini, F., Giacomini, M., DeJean, D., Vanstone, M., Winsor, S., \& Smith, A. (2013). Chronic disease patients' experiences with accessing health care in rural and remote areas: a systematic review and qualitative meta-synthesis. Ontario Health Technology Assessment Series, 13(15), 1.

Burholt, V. (2012). The dimensionality of "place attachment" for older people in rural areas of South West England and Wales. Environment and Planning A, 44(12), 2901-2921. DOI: http://doi.org/10.1068/a4543

Carpiano, R.M. (2009). Come take a walk with me: The "go-along" interview as a novel method for studying the implications of place for health and well-being. Health \& Place, 15(1), 263-272. DOI: http://dx.doi.org/10.1016/j.healthplace.2008.05.003

Chapman, S.A. (2009). Ageing well: emplaced over time. International Journal of Sociology and Social Policy, 29(1/2), 27 - 37. DOI: http://dx.doi.org/10.1108/01443330910934691

Charmaz, K. (2014). Constructing grounded theory: Second edition. London: Sage

Clifford, D. (2012). Voluntary sector organisations working at the neighbourhood level in England: patterns by local area deprivation. Environment and Planning A,44(5), 1148-1164. https://doi.org/10.1068/a44446

Cummins, S., Curtis, S., Diez-Roux, A. V., \& Macintyre, S. (2007). Understanding and representing 'place'in health research: a relational approach. Social Science \& Medicine, 65(9), 1825-1838. https://doi.org/10.1016/j.socscimed.2007.05.036

Department for environment food \& rural affairs [Defra] (2019). Statistical digest of rural England. June 2019 edition. Accessed July 2019: https://assets.publishing.service.gov.uk/government/uploads/system/uploads/attachment_data/file/812 438/06 Statistical Digest of Rural England 2019 June edition.pdf

Farmer, J., Iversen, L., Campbell, N. C., Guest, C., Chesson, R., Deans, G., \& MacDonald, J. (2006). Rural/urban differences in accounts of patients' initial decisions to consult primary care. Health \& Place, 12(2), 210-221. https://doi.org/10.1016/j.healthplace.2004.11.007

Faugier, J. \& Sargeant, M. (1997). Sampling hard to reach populations. Journal of Advanced Nursing, 26(4), 790-797. https://doi.org/10.1046/j.1365-2648.1997.00371.x

Fayaz, A., Croft, P., Langford, R.M., Donaldson, L.J. \& Jones, G.T (2016). Prevalence of chronic pain in the UK: a systematic review and meta-analysis of population studies. BMJ Open, 6(6), p.e010364. DOI: 10.1136/bmjopen-2015-010364 
Finlay, J., Franke, T., McKay, H., \& Sims-Gould, J. (2015). Therapeutic landscapes and wellbeing in later life: Impacts of blue and green spaces for older adults. Health \& Place, 34, 97-106. https://doi.org/10.1016/j.healthplace.2015.05.001

Gannon, B., Finn, D. \& O'Gorman, D. (2013). The cost of chronic pain: an analysis of a regional pain management service in Ireland. Pain Medicine, 14(10), 1518-1528. DOI:10.1111/pme.12202/full

Gudmannsdottir, G.D. \& Halldorsdottir, S. (2009). Primacy of existential pain and suffering in residents in chronic pain in nursing homes: a phenomenological study. Scandinavian Journal of Caring Sciences, 23(2), 317-327. DOI: http://doi.org/10.1111/j.1471-6712.2008.00625.x

Heley, J. \& Jones, L. (2012). Relational rurals: some thoughts on relating things and theory in rural studies. Journal of Rural Studies, 28(3), 208-217. https://doi.org/10.1016/j.jrurstud.2012.01.011

Hennessy, C., Jones, R., Phippen, A., Maramba, I., Giarchi, G., Lankshear, G., Means, R., Curry, N., Parkhurst, G., Musselwhite, C., Shergold, I., Biggs, I., Evans, S., Bailey, J., Buzzo, D. Jones, K., Galvin, K., Todres, L., Staelens, Y., Fenge, L., Read, R., Cash, M., Burholt, V., Phillips, J., Smithson, J., Fisher, R. (2013). Grey and pleasant land? An interdisciplinary exploration of the connectivity of older people in rural civic society: NDA findings 30 report. Available online: http://www.newdynamics.group.shef.ac.uk/view-all-findings.html

Hinck, S. (2004). The lived experience of oldest-old rural adults. Qualitative Health Research, 14(6), 779-91. DOI: http://doi.org/10.1177/1049732304265774

HM Government (2018). A connected society: a strategy for tackling loneliness. Accessed online (July 2019):

https://assets.publishing.service.gov.uk/government/uploads/system/uploads/attachment data/file/750 909/6.4882 DCMS Loneliness Strategy web Update.pdf

Hunhammar, C., Nilsson-Wikmar, L. \& Löfgren, M. (2009). Striving to master variable pain: An interview study in primary care patients with non-specific long-term neck/shoulder pain. Journal of Rehabilitation Medicine, 41(9), 768-774. DOI: http://doi.org/10.2340/16501977-0421

Hyde, M., Wiggins, R.D., Higgs, P. \& Blane, D.B. (2003). A measure of QoL in early old age: The theory, development and properties of a needs satisfaction model (CASP-19). Aging Mental Health, 7(3), 186-194. DOI: http://doi.org/10.1080/1360786031000101157

Kusenbach, M. (2003). Street phenomenology the go-along as ethnographic research tool. Ethnography, 4(3), 455-485. DOI: https://doi.org/10.1177/146613810343007

Lawton, M. P. (1983). Environment and other determinants of well-being in older people. The Gerontologist, 23(4), 349-357. https://doi.org/10.1093/geront/23.4.349

Lawton, M. P., \& Nahemow, L. (1973). Ecology and the aging process. In C. Eisdorfer and M. P. Lawton (Eds) The psychology of adult development and aging, pp. 619-674. Washington, DC, US: American Psychological Association.

Lien, L. L., Steggell, C. D., \& Iwarsson, S. (2015). Adaptive strategies and person-environment fit among functionally limited older adults aging in place: a mixed methods approach. International Journal of Environmental Research and Public Health, 12(9), 11954-11974. https://doi.org/10.3390/ijerph120911954

Macintyre, S., Ellaway, A., \& Cummins, S. (2002). Place effects on health: how can we conceptualise, operationalise and measure them?. Social Science \& Medicine, 55(1), 125-139. https://doi.org/10.1016/S0277-9536(01)00214-3

Mackichan, F., Adamson, J., \& Gooberman-Hill, R. (2013). 'Living within your limits': activity restriction in older people experiencing chronic pain. Age and Ageing, 42(6), 702-708. https://doi.org/10.1093/ageing/aft119

Means, R., Burholt, V., \& Hennessy, C. H. (2014). Towards connectivity in a Grey and Pleasant Land?. In C.H. Hennessy, V., R. Means and V. Burholt (Eds) Countryside connections: older people, community and place in rural Britain, pp. 245-276. Policy Press. 
Menec, V. H., Hutton, L., Newall, N., Nowicki, S., Spina, J., \& Veselyuk, D. (2015). How 'agefriendly' are rural communities and what community characteristics are related to age-friendliness? The case of rural Manitoba, Canada. Ageing \& Society, 35(1), 203-223. https://doi.org/10.1017/S0144686X13000627

Morden, A., Jinks, C., \& Ong, B.N. (2012). Rethinking "risk" and self-management for chronic illness. Social Theory \& Health, 10(1), 78-99. http://doi.org/10.1057/sth.2011.20

National Trust (2017). Playing our part: What does the nation need from the National Trust in the 21st century? Accessed online (July 2019): https://nt.global.ssl.fastly.net/documents/national-trust-playingour-part.pdf

Ndao-Brumblay, S.K., \& Green, C.R. (2010). Predictors of complementary and alternative medicine use in chronic pain patients. Pain Medicine, 11(1), 16-24. https://doi.org/10.1111/j.15264637.2009.00767.x

NHS England (2019). The NHS long term plan. Accessed online (March 2020): https://www.longtermplan.nhs.uk/wp-content/uploads/2019/01/nhs-long-term-plan-june-2019.pdf

Oxford Consultants for Social Inclusion (2009). Mapping the level of need: assessing the social exclusion of older people in rural areas. London: Report for the Cabinet Office, Social Exclusion Task Force.

O'Sullivan, R., Donnelly, N., McGill, P., Breen, C., O'Shea, E., Walsh, K., \& Scharf, T. (2012). Exploring community perceptions of the relationship between age and social exclusion in rural areas. Quality in Ageing and Older Adults. ISSN: 1471-7794; 9 March 2012.

Philip, L., Roberts, A., Currie, M. \& Mort, A. (2015). Technology for older adults: maximising personal and social interaction: exploring opportunities for ehealth to support the older rural population with chronic pain. Scottish Geographical Journal, 131(3-4), 181-193. DOI: http://doi.org/10.1080/14702541.2014.978806

Philip, L. J., \& Shucksmith, M. (2003). Conceptualizing social exclusion in rural Britain. European Planning Studies, 11(4), 461-480.

Philo, C., Parr, H., \& Burns, N. (2017). The rural panopticon. Journal of Rural Studies, 51, 230-239. https://doi.org/10.1016/j.jrurstud.2016.08.007

Prosser, J. (2006). Researching with visual images: some guidance notes and a glossary for beginners. ESRC National Centre for Research Methods. Available online: http://eprints.ncrm.ac.uk/481/1/0606_researching_visual_images.pdf

Rachele, J. N., Washington, T. L., Cuddihy, T. F., Barwais, F. A., \& McPhail, S. M. (2013). Valid and reliable assessment of wellness among adolescents: Do you know what you're measuring? International Journal of Wellbeing, 3(2).

Raymond, C. M., Brown, G., \& Weber, D. (2010). The measurement of place attachment: Personal, community, and environmental connections. Journal of Environmental Psychology, 30(4), 422-434. https://doi.org/10.1016/j.jenvp.2010.08.002

Richardson, J. C., Moore, A. J., Bernard, M., Jordan, K. P., \& Sim, J. (2015). Living well with chronic pain in later life: The role and meaning of activity and involvement. Activities, Adaptation \& Aging, 39(3), 200-213. https://doi.org/10.1080/01924788.2015.1063329

Rowles, G.D. (1978). Prisoners of space? Exploring the geographical experience of older people. Westview Press.

Rowles, G.D. (1983). Place and personal identity in old age: observations from Appalachia. Journal of Environmental Psychology, 3(4), 299-313. https://doi.org/10.1016/S0272-4944(83)80033-4

Rowles, G. D. \& Bernard, M. (2013). Environmental gerontology: making meaningful places in old age. Springer: New York. 
Rural England (2017). Older people in rural areas: vulnerable due to poor health paper. Accessed online (July 2019): https://ruralengland.org/reports/rural-vulnerability-older-people/

Sacker, A., Ross, A., MacLeod, C. A., Netuveli, G., \& Windle, G. (2017). Health and social exclusion in older age: evidence from Understanding Society, the UK household longitudinal study. Journal of Epidemiological Community Health, 71(7), 681-690. http://dx.doi.org/10.1136/jech-2016-208037

Saunders, B., Sim, J., Kingstone, T., Baker, S., Waterfield, J., Bartlam, B., Burroughs, H. \& Jinks, C. (2017). Saturation in qualitative research: exploring its conceptualization and operationalization. Quality \& Quantity, 1-15. https://doi.org/10.1007/s11135-017-0574-8

Scharf, T., \& Bartlam, B. (2006). Rural disadvantage: quality of life, disadvantage amongst older people in rural areas. London: Commission for rural communities.

Schofield, P., O'Mahony, S., Collett, B., \& Potter, J. (2008). Guidance for the assessment of pain in older adults: a literature review. British Journal of Nursing, 17(14), 914-918. https://doi.org/10.12968/bjon.2008.17.14.30659

Sherry, E., \& Shortall, S. (2019). Methodological fallacies and perceptions of rural disparity: How rural proofing addresses real versus abstract needs. Journal of Rural Studies, 68, 336-343. https://doi.org/10.1016/j.jrurstud.2018.12.005

Shucksmith, M., 2003. Social exclusion in rural areas: A review of recent research. Aberdeen, Scotland: Arkleton Centre for Rural Development Research.

Silverman, D. (2013). Doing qualitative research: A practical handbook. SAGE Publications Limited.

Smith, A. E., Sim, J., Scharf, T., \& Phillipson, C. (2004). Determinants of quality of life amongst older people in deprived neighbourhoods. Ageing \& Society, 24(5), 793-814. https://doi.org/10.1017/S0144686X04002569

Sofaer-Bennett, B., Holloway, I., Moore, A., Lamberty, J., Thorp, T. \& O’Dwyer, J. (2007). Perseverance by older people in their management of chronic pain: a qualitative study. Pain Medicine, 8(3), 271-280. http://doi.org/10.1111/j.1526-4637.2007.00297.x

Staffordshire County Council (2018). Staffordshire Moorlands: Annual Report 2017-18. Accessed online (March 2020): https://democracy.highpeak.gov.uk/uuCoverPage.aspx?bcr=1.

Stuckler, D., Reeves, A., Loopstra, R., Karanikolos, M., \& McKee, M. (2017). Austerity and health: the impact in the UK and Europe. European Journal of Public Health,27(suppl_4), 18-21. https://doi.org/10.1093/eurpub/ckx167

Tollefson, J., Usher, K. \& Foster, K. (2011). Relationships in pain: the experience of relationships to people living with chronic pain in rural areas. International Journal of Nursing Practice, 17(5), 478485. http://doi.org/10.1111/j.1440-172X.2011.01963.x

Treede, R. D., Rief, W., Barke, A., Aziz, Q., Bennett, M. I., Benoliel, R., Cohen, M., Evers, S., Finnerup, N. B., First, M. B., Giamberardino, M. A., Kaasa, S., Kosek, E., Lavand'homme, P., Nicholas, M., Perrot, S., Scholz, J., Schug, S., Smith, B. H., Svensson, P., Vlaeyen, J. W., \& Wang, S. J. (2015). A classification of chronic pain for ICD-11. Pain, 156(6), 1003-1007. http://doi.org/10.1097/j.pain.0000000000000160

Wahl, H. W., Iwarsson, S., \& Oswald, F. (2012). Aging well and the environment: Toward an integrative model and research agenda for the future. The Gerontologist, 52(3), 306-316. https://doi.org/10.1093/geront/gnr154

Walsh, K., Scharf, T., \& Keating, N. (2017). Social exclusion of older persons: a scoping review and conceptual framework. European Journal of Ageing, 14(1), 81-98. https://doi.org/10.1007/s10433-018$\underline{0483-2 .}$.

Wenger, G. C. (2001). Myths and realities of ageing in rural Britain. Ageing \& Society, 21(1), 117-130. http://doi.org/doi:10.1017/S0144686X01008042 
Wenger, G. C., \& Burholt, V. (2004). Changes in levels of social isolation and loneliness among older people in a rural area: a twenty-year longitudinal study. Canadian Journal on Aging, 23(02), 115-127. https://doi.org/10.1353/cja.2004.0028

Winterton, R., Warburton, J., Keating, N., Petersen, M., Berg, T., \& Wilson, J. (2016). Understanding the influence of community characteristics on wellness for rural older adults: A meta-synthesis. Journal of Rural Studies, 45, 320-327. https://doi.org/10.1016/j.jrurstud.2015.12.010

World Health Organisation (2009). Health promotion glossary update. Accessed online (July 2019): https://www.who.int/healthpromotion/about/HPR\%20Glossary_New\%20Terms.pdf 
Table 1. Participant demographic information

\begin{tabular}{|c|c|c|c|c|c|c|c|}
\hline 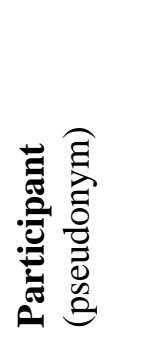 & 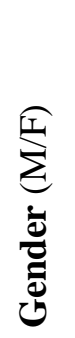 & 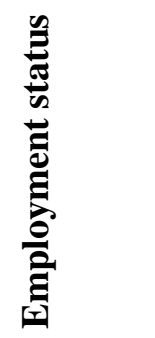 & 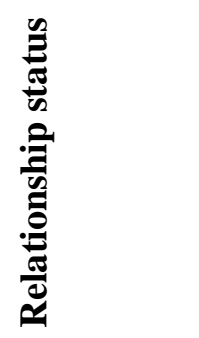 & 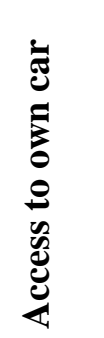 & 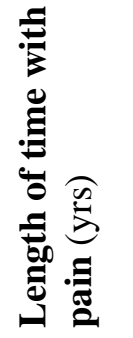 & 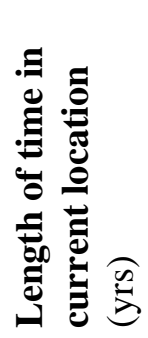 & 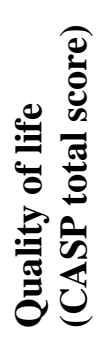 \\
\hline Anne & $\mathrm{F}$ & Retired & Widow & No & $10-12$ & $>50$ & 35 \\
\hline Barbara & $\mathrm{F}$ & Retired & Widow & Yes* & $4-5$ & 12 & 32 \\
\hline Catherine & $\mathrm{F}$ & Retired & Single & No & 3 & 10 & 41 \\
\hline David & $\mathrm{M}$ & Retired & Married & Yes & 40 & 12 & 44 \\
\hline Edward & M & Retired & Married & Yes & 4 & 10 & 30 \\
\hline Frances & $\mathrm{F}$ & Retired & Single & Yes & 20 & 45 & 49 \\
\hline George & $\mathrm{M}$ & Retired & Married & Yes* & 25 & 1.5 & 27 \\
\hline Henry & M & Full time & Co-habiting & Yes & 3 & 14 & 39 \\
\hline
\end{tabular}

Tables notes: all participants were White British (99 per cent of wider population).

*Participants owned their own car but described limiting driving to known local routes

Table 3. Contribution of data per participant

\begin{tabular}{lccl}
\hline Participant & Stage 1 interview & CASP-19 & Stage 2: type of interview \\
\hline Anne & $\checkmark$ & $\checkmark$ & Go-along \\
Barbara & $\checkmark$ & $\checkmark$ & Photo-elicitation \\
Catherine & $\checkmark$ & $\checkmark$ & In-depth interview \\
David* & $\checkmark$ & $\checkmark$ & In-depth interview \\
Edward** & $\checkmark$ & $\checkmark$ & Declined \\
Frances & $\checkmark$ & $\checkmark$ & Photo-elicitation \\
George*** & $\checkmark$ & $\checkmark$ & Declined \\
Henry & $\checkmark$ & $\checkmark$ & Go-along \\
\hline
\end{tabular}

* David's wife Diane was also present for the interviews

**Edward's wife Ethel was also present for the interview

***George's wife Gail was present for the interview 
Table 2. Participant health characteristics

\begin{tabular}{|c|c|c|c|c|c|}
\hline Participant & $\begin{array}{l}\text { Location of } \\
\text { chronic pain }\end{array}$ & Stated cause of pain & $\begin{array}{l}\text { Pain descriptors } \\
\text { (summarised) }\end{array}$ & $\begin{array}{l}\text { Impact of chronic pain } \\
\text { (activities prevented or limited) }\end{array}$ & Pain management strategies \\
\hline Anne & $\begin{array}{l}\text { Lower back, } \\
\text { shoulder, hip, } \\
\text { hands }\end{array}$ & Osteoarthritis & $\begin{array}{l}\text { Fluctuating, gnawing, } \\
\text { aching, rising when active }\end{array}$ & $\begin{array}{l}\text { Walking, climbing stairs, } \\
\text { household tasks are limited, } \\
\text { getting on bus }\end{array}$ & Painkillers only \\
\hline Barbara & $\begin{array}{l}\text { Shoulder, hands, } \\
\text { feet }\end{array}$ & Osteoarthritis & $\begin{array}{l}\text { Fluctuating, knife-like, } \\
\text { stabbing, widespread }\end{array}$ & $\begin{array}{l}\text { Walking, washing, cleaning } \\
\text { (self/house), cooking }\end{array}$ & Painkillers only \\
\hline Catherine & $\begin{array}{l}\text { Hip, right } \\
\text { buttock }\end{array}$ & Muscular pain & $\begin{array}{l}\text { Fluctuating, aching, occurs } \\
\text { when standing too long }\end{array}$ & $\begin{array}{l}\text { Cooking, walking further than } \\
50 \text { metres, gardening (stopped) }\end{array}$ & Painkillers only \\
\hline David & $\begin{array}{l}\text { Lower back, } \\
\text { elbow, hands }\end{array}$ & $\begin{array}{l}\text { Osteoarthritis } \\
\text { (multiple triggers) }\end{array}$ & $\begin{array}{l}\text { Fluctuating, like toothache, } \\
\text { episodic, intense, varied } \\
\text { across sites }\end{array}$ & $\begin{array}{l}\text { Opening jam jars (loss of grip } \\
\text { strength), home maintenance, } \\
\text { gardening, lying down in a bed }\end{array}$ & $\begin{array}{l}\text { Painkillers, physiotherapy } \\
\text { exercises, chiropractic }\end{array}$ \\
\hline Edward & $\begin{array}{l}\text { Lower back, } \\
\text { right hip }\end{array}$ & Osteoarthritis & $\begin{array}{l}\text { Fluctuating, aching but } \\
\text { without spasms* }\end{array}$ & $\begin{array}{l}\text { Walking, getting up from seated } \\
\text { position, standing over a cooker, } \\
\text { gardening }\end{array}$ & Painkillers only \\
\hline Frances & Hip, lower back & Sciatica & $\begin{array}{l}\text { Fluctuating, aching rising } \\
\text { to sharp pain }\end{array}$ & $\begin{array}{l}\text { Driving long distances, walking } \\
\text { long distances, gardening }\end{array}$ & Painkillers, reflexology, yoga \\
\hline George & Feet, ankles & Osteoarthritis & $\begin{array}{l}\text { Constant, tenderness, } \\
\text { aching }\end{array}$ & Farming. gardening, walking & Painkillers, chiropractic \\
\hline Henry & $\begin{array}{l}\text { Abdomen, lower } \\
\text { back }\end{array}$ & Post-shingles & Constant tingling & Walking long distances & Painkillers only \\
\hline
\end{tabular}

*Identified by participant as important as this contradicted the information provided on his prescribed medication ("for spasm-related pain"). 


\section{APPENDIX 1}

\section{ONE-TO-ONE INTERVIEW TOPIC GUIDE}

\section{Background information}

- Age / sex / ethnicity / relationship status

- Family network and frequency of contact

- Work history

- Type of house and length of stay

\section{Health and pain experience}

- How are you in terms of your health?

- Do you have any long-standing health conditions?

- Can you describe your pain to me?

- Location of pain

- Intensity

- When did it start?

- What do you think causes your pain?

- How does your pain interfere with daily life?

- What factors are important in maintaining/improving your health?

\section{Coping strategies}

- How do you cope with your pain?

- Do you receive any help and support from anyone?

- Who do you talk to about your pain?

- Do you consider yourself to be a resilient person?

\section{Social activities}

- What activities or hobbies do you take part in?

- Have you had to stop any activities?

- Are you a member of any local groups? Can you tell me about these?

\section{Surrounding environment}

- Housing / location history - have you always lived in a rural area?

- Why did you decide to live here?

- What does this house mean to you?

- What does this area mean to you?

- Can you access the services that you need?

- Do you feel part of the community here? 


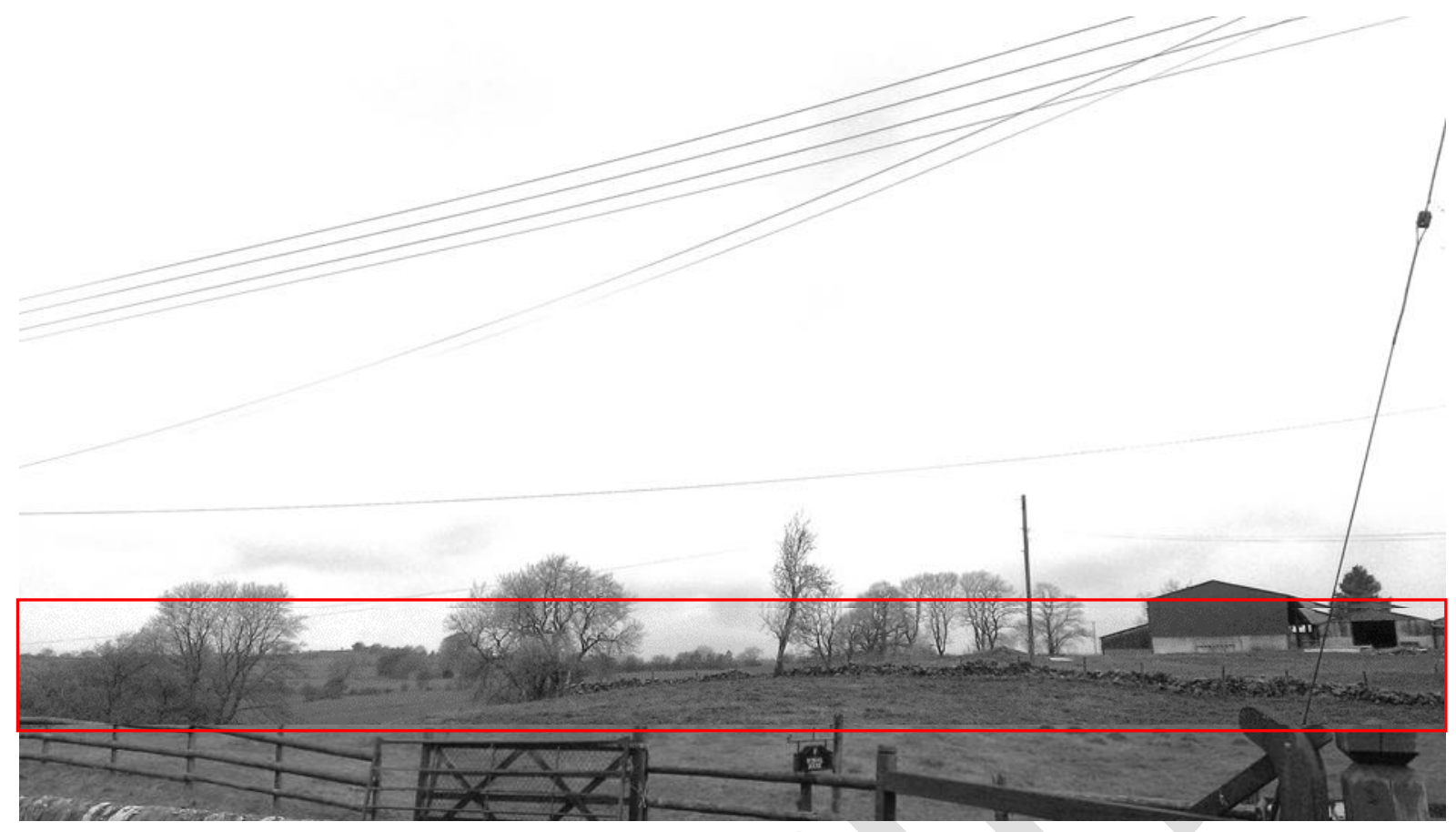

Figure 1. Damaged dry-stone walls

Extract from fieldnotes: The highlighted section indicates the length of damaged wall. This is visible from George's kitchen window and provides a daily reminder of a lost sense of connection to occupation (farming), identity (farmer), and environment. 


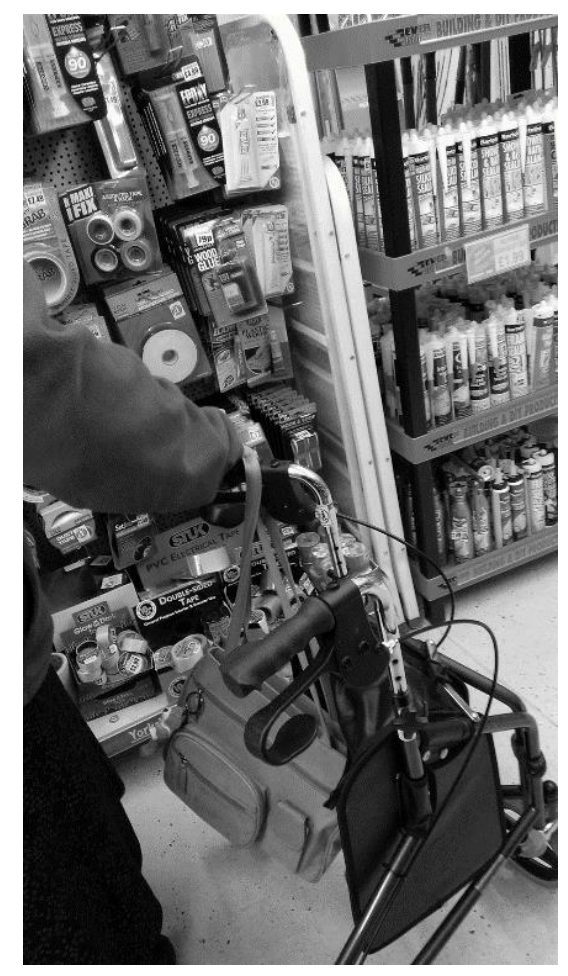

Figure 2. Go-along with Anne - Using her walker

Extract from fieldnotes: Pushing and leaning on her walker simultaneously Anne investigated each section of each of the aisles in the shop. Anne hung her handbag from one of the handles on the walker and carried her magnifying glass in the top of the satchel on her walker using this sporadically to take a closer look at particular items and prices. 


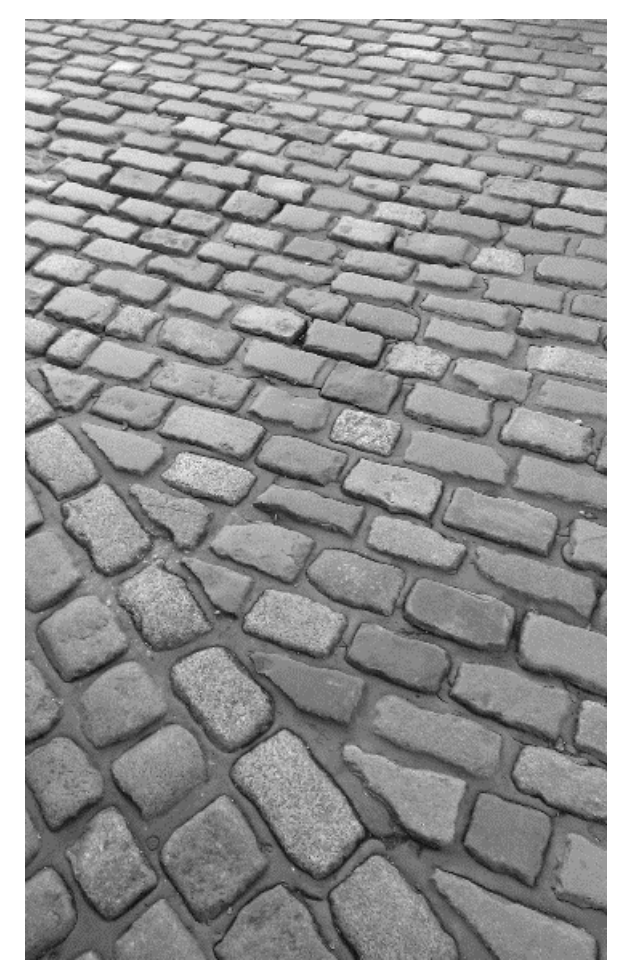

Figure 3. Go-along with Anne - environmental hazard

Extract from fieldnotes: The cobbles of the car park were raised and seemed unhelpful for somebody using a wheeled walker. The early morning rain had left a slippery top to the stones and the runnels between them made pushing three wheels sufficiently tricky. This car park had been designed to be pedestrian friendly, with cars having to drive slowly across the cobbles. However, this appeared to make Anne's life difficult as she bounced the walker over and between cobbles taking extra care not to slip or lose her balance. 


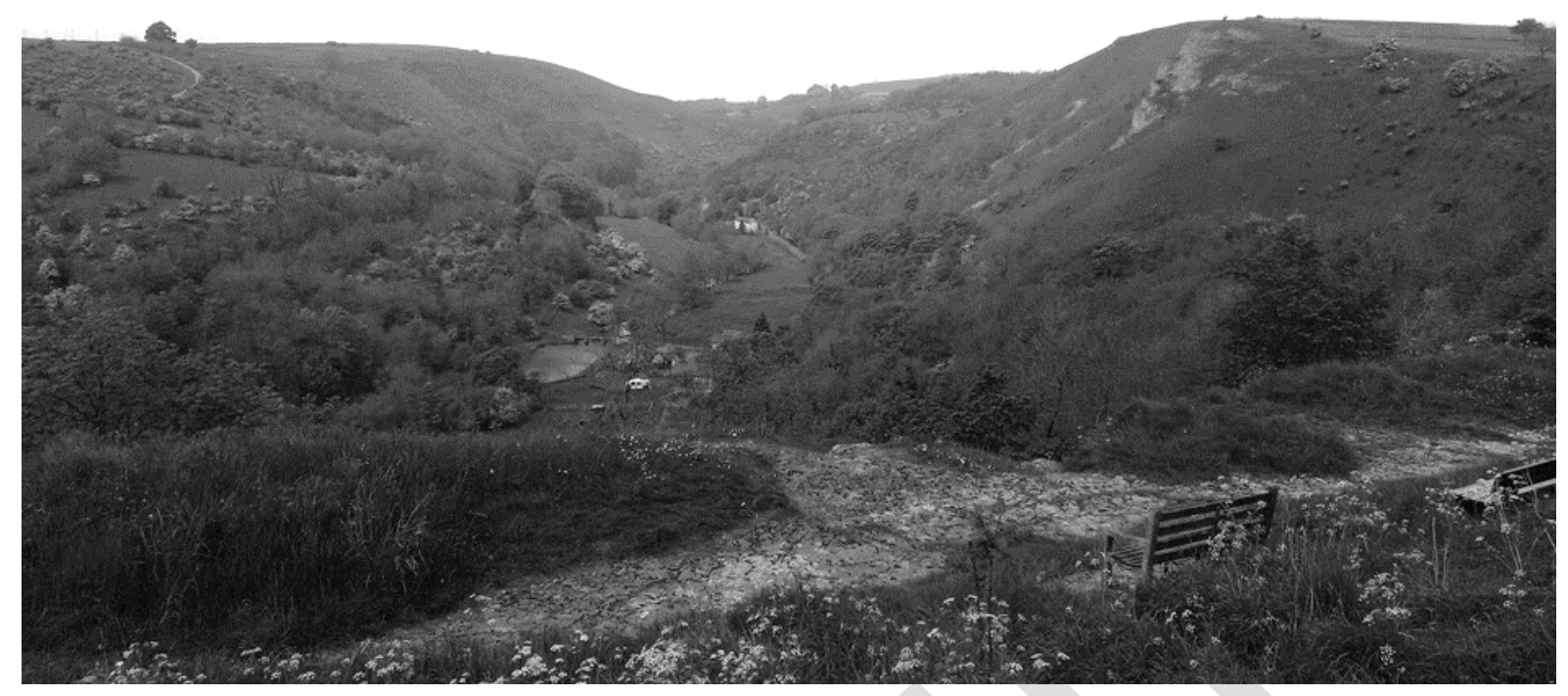

Figure 4. Photograph of Henry's "favourite beauty spot" which he took me to during the go-along 


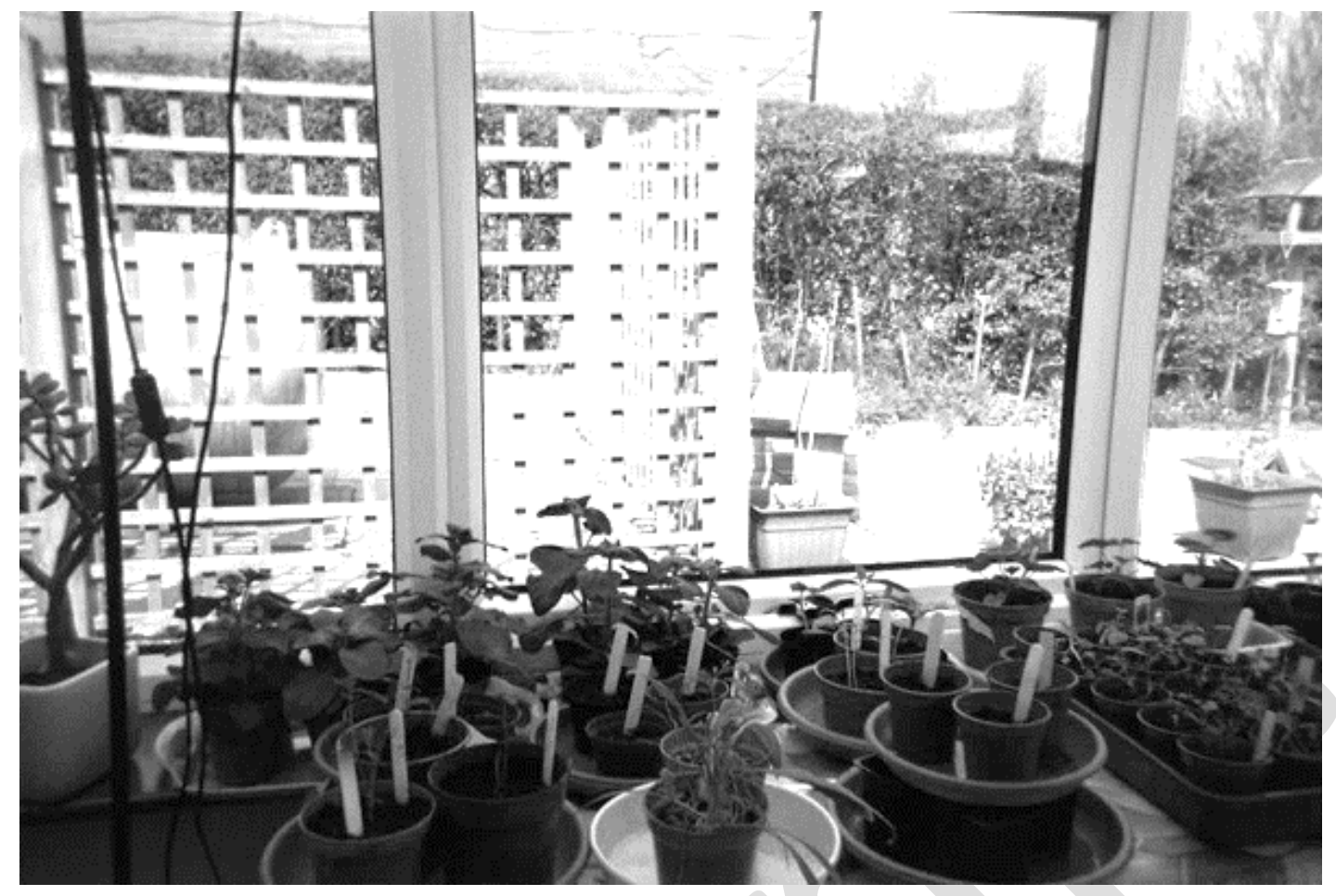

Figure 5. Frances discussing her passion for gardening 


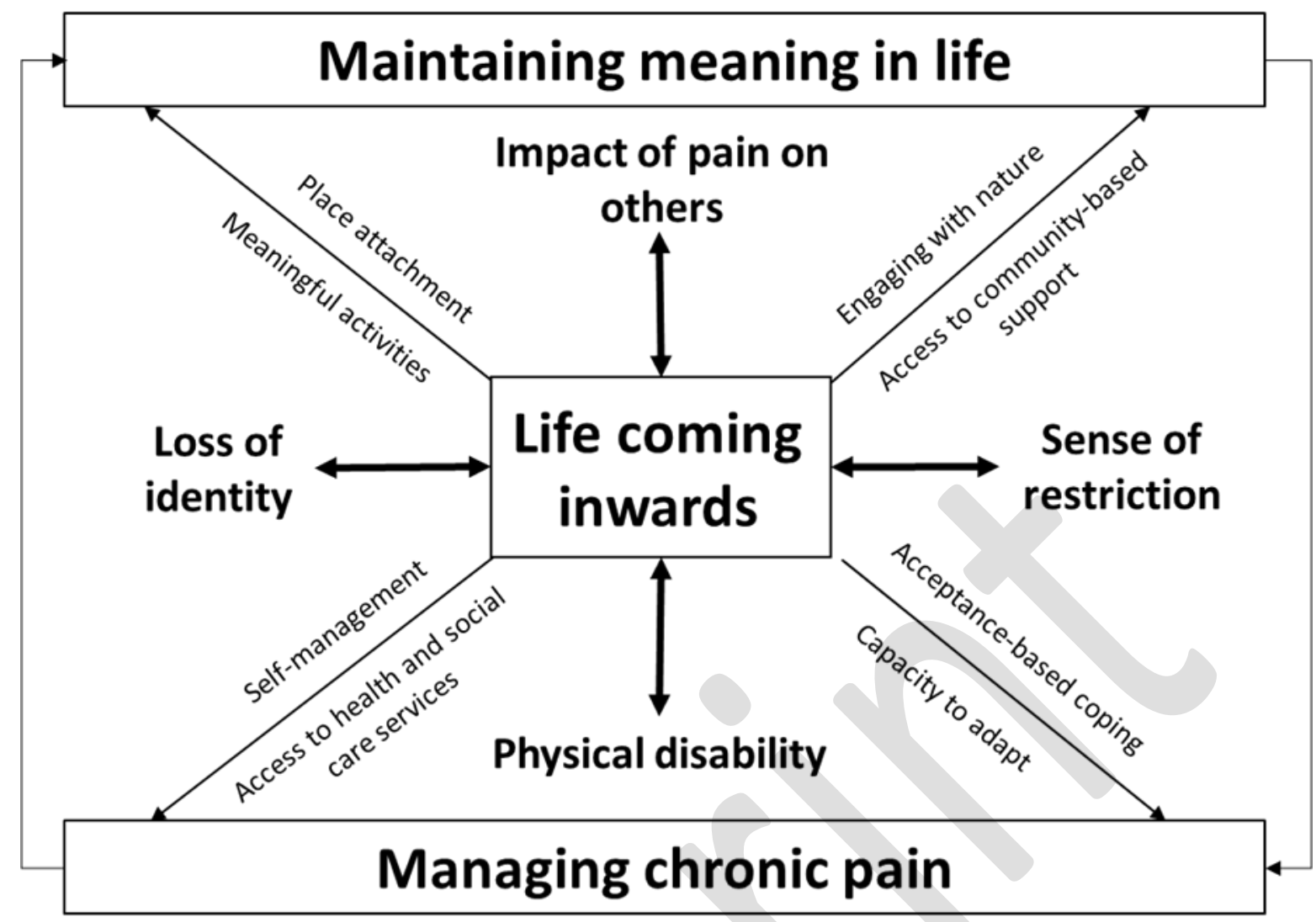

Figure 6. Conceptual diagram of factors shaping (or not) ageing well with chronic pain in rural areas 